Acta vet. scand. $1986,27,453-455$.

Brief Communication

\title{
SEROLOGICAL CHARACTERIZATION OF ACTINOBACILLUS PLEUROPNEUMONIAE STRAINS AND PROPOSAL OF A NEW SEROTYPE: SEROTYPE 12
}

Until now 11 serotypes of Actinobacillus pleuropneumoniae have been described (Nicolet 1971, Gunnarsson 1980, Nielsen 1982, Rosendal \& Boyd 1982, Nielsen \& O'Connor 1984, Nielsen 1985, Kamp 1986). Recently a hitherto unrecognized serotype was isolated from 9 Danish outbreaks of pleuropneumonia in pigs. The origin of the strains is given in Table 1 . From 3 herds the unrecognized serotype was found in 2 to 3 pigs submitted for necropsy at different times. The present study describes the serological properties of the 13 isolated strains.

Table 1. Origin of 13 Danish strains of Actinobacillus pleuropneumoniae examined in serological tests.

\begin{tabular}{|c|c|c|c|}
\hline $\begin{array}{c}\text { Strain } \\
\text { designation }\end{array}$ & Isolated from & Age of pigs & Herd category \\
\hline 9499 & Acute pleuropneumonia & 4 days & Sow herd, conventional \\
\hline 1096 &, & 6 months & Sow herd, SPF ${ }^{\star}$ \\
\hline 9272 & , & 2 months & Sow herd, SPF \\
\hline 6113 & ” & 3 months & Sow herd, conventional \\
\hline 2053 & 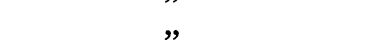 & 2 months & Sow herd, conventional \\
\hline 9680 & , & 2 months & Sow herd, conventional \\
\hline 10199 & , & 3 months & same as 9680 \\
\hline 6599 & , & 2 months & Sow herd, SPF \\
\hline 16077 & ” & 3 months & same as 6599 \\
\hline 1831 & 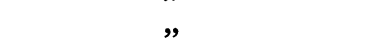 & 2 months & Sow herd, SPF \\
\hline 8329 & , & 4 months & same as 1831 \\
\hline 5382 & " & 4 months & same as 1831 \\
\hline 11705 & Septicaemia & 6 weeks & Sow herd, conventional \\
\hline
\end{tabular}

* $=$ specific pathogen free herd.

The cultural and biochemical characteristics of the strains were consistent with earlier descriptions of A. pleuropneumoniae (Kilian 1976, Biberstein et al. 1977, Nielsen 1982). The strains were examined serologically by the indirect haemagglutination test and by gel diffusion as described earlier (Nielsen \& $O^{\prime}$ Connor 1984). Reference strains representing serotypes 1 through 11 were: Shope 4071, S1536, S1421, M62, K17, Fem $\phi$, WF83, 405, CVJ13261, 56153. 
Sheep red cells sensitized with capsular extracts (heated and non-heated) of the 13 strains were agglutinated to high titers $(1: 2560$ to $1: 10.240)$ by rabbit antiserum produced against whole-cell antigens of strains 1096 and 8329. Agglutination was not observed with antisera for serotypes 1 through 11 .

Cross absorptions involving strains 1096 and 8329 and their respective antisera resulted in complete removal of agglutinating activity towards the 2 strains and towards strains 11705 , 9499, 5382, 1831, 9272, 6599, 16077, 6113, 2053, 9680 and 10199 (Table 2).

Table 2. IHA titers obtained with various antigen preparations of strains 8329 and 1096 against rabbit antisera produced against whole-cell antigens (6-h cultures). Sera were tested before and after homologous and heterologous absorption.

\begin{tabular}{|c|c|c|c|c|c|c|}
\hline \multirow[b]{3}{*}{ Antigen } & \multicolumn{6}{|c|}{ Antiserum } \\
\hline & \multirow{2}{*}{$\begin{array}{c}8329 \\
\text { unabsorbed }\end{array}$} & \multicolumn{2}{|c|}{ absorbed with } & \multirow{2}{*}{$\begin{array}{c}1096 \\
\text { unabsorbed }\end{array}$} & \multicolumn{2}{|c|}{ absorbed with } \\
\hline & & 8329 & 1096 & & 1096 & 8329 \\
\hline 8329, Ce & 10.240 & - & - & 5120 & - & - \\
\hline $8329, \mathrm{Ce}$ & 5120 & - & - & 2560 & - & - \\
\hline 1096, Ce & 10.240 & - & - & 5120 & - & - \\
\hline $1096, \mathrm{Ce} 100^{\circ}$ & 5120 & - & - & 2560 & - & - \\
\hline
\end{tabular}

$\mathrm{Ce}=$ Capsular extracts.

Ce, $100^{\circ}=$ heat-treated capsular extracts.

一 = no reaction.

Titers are given as reciprocals of the highest serum dilution giving positive reaction.

When capsular extracts (heated and non-heated) of strains 1096 and 8329 were used as antigens in gel diffusion tests against their homologous antisera two type-specific precipitation lines were seen: one broad and fuzzy line situated near the antigen well and another more dense peripheral line. In addition, two precipitation lines showing reaction of identity between all serotypes were seen with non-heated antigen. In comparative analysis of the 13 strains against antisera 1096 and 8329 the strains proved identical. Cross absorptions involving the 13 strains resulted in complete removal of all precipitins from antisera 1096 and 8329.

Serotypes of A. pleuropneumoniae possess type-specific antigenic determinants of capsular origin which can be demonstrated by immunodiffusion tests and by indirect haemagglutination 
tests. Common species specific antigens have also been demonstrated in all serotypes (Nicolet 1971, Gunnarsson 1980, Nielsen \& O'Connor 1984, Nielsen 1985).

The 13 strains of A. pleuropneumoniae examined in the present study possessed two type-specific antigenic determinants of capsular origin as well as common species-specific antigens. As the strains are antigenically homogeneous and serologically distinct from serotypes 1 through 11 the strains are proposed to be referred to a new serotype, designated serotype 12 with strain 8329 as the type strain.

R. Nielsen

The National Veterinary Laboratory, Copenhagen, Denmark.

\section{REFERENCES}

Biberstein, E. L., A. Gunnarsson \& B. Hurwell: Cultural and biochemical criteria for the identification of Haemophilus spp. from swine. Amer. J. vet. Res. 1977, 38, 7-11.

Gunnarsson, A.: Haemophilus pleuropneumoniae syn parahaemolyticus. An antigenic and diagnostic study. Thesis, Uppsala 1980.

Kamp, E.: Personal communication.

Kilian, M.: A taxonomic study of the genus Haemophilus with the proposal of a new species. Thesis, Århus 1976.

Nicolet, J.: Sur l'hemophilose du porc. III. Differénciation sérologique de Haemophilus parahaemolyticus. (Haemophilus infections in pigs. III. Serological studies on Haemophilus parahaemolyticus. Zbl. Bakt. 1971, 216, 487-495.

Nielsen, R.: Haemophilus pleuropneumoniae infection in pigs. Thesis, Copenhagen 1982.

Nielsen, R.: Serological characterization of Haemophilus pleuropneumoniae (Actinobacillus pleuropneumoniae) strains and proposal of a new serotype: serotype 9 . Acta vet. scand. 1985, 26, $501-512$.

Nielsen, R.: Serological characterization of Haemophilus pleuropneumoniae (Actinobacillus pleuropneumoniae) strains and proposal of a new serotype: serotype 10. Acta vet. scand. 1985, 26, $581-585$.

Nielsen, R. \& P. J. O'Connor: Serological characterization of 8 Haemophilus pleuropneumoniae strains and proposal of a new serotype: serotype 8. Acta vet. scand. 1984, 25, 96-106.

Rosendal, $S$. \& A. Boyd: Haemophilus pleuropneumoniae serotyping. J. clin. Microbiol. 1982, 16, 840-843.

(Received October 17, 1986).

Reprints may be requested from: R. Nielsen, the National Veterinary Laboratory, Bülowsvej 27, DK-1870 Frederiksberg C, Denmark. 